\title{
A genetic marker for rheumatic heart disease
}

\author{
C N A RAJAPAKSE, K HALIM, * I AL-ORAINEY, M AL-NOZHA, A K AL-ASKA \\ From the Departments of ${ }^{*}$ Pathology and Medicine, King Khalid University Hospital, King Saud University, \\ Riyadh, Saudi Arabia
}

SUMMARY The frequency of antigen types (A, B, C, and DR) in an unselected group of 25 patients with chronic rheumatic heart disease and an unselected group of 15 patients with acute rheumatic fever was compared with that in a group of 100 healthy volunteers. All patients and controls were Arabs of Saudi origin. Only the frequency of HLA-DR4 was significantly different in the controls and the patient groups-controls $12 \%$, chronic rheumatic heart disease $72 \%$, acute rheumatic fever 53\%, both patient groups together $65 \%$ (relative risk 13.6 with $95 \%$ confidence interval 10.5-16.7). Eighty three per cent of 12 patients with mitral stenosis and $70 \%$ of seven with aortic incompetence had HLA-DR4 antigen. In 17 non-Saudi Arab patients who had acute rheumatic fever or chronic rheumatic heart disease, the frequency of HLA-DR4 was identical $(65 \%)$ to that in Saudi patients.

These findings may have implications for the pathogenesis of rheumatic fever and rheumatic heart disease.

It has long been suggested that genetic factors contribute towards a predisposition to rheumatic fever and rheumatic heart disease. ${ }^{1}$ Though several studies of HLA types have been undertaken none has conclusively shown a marker for such a predisposition. Caughey et al found an increase in frequency of HLA-A3 and HLA-A8 and a decrease in frequency of HLA-A10 in 50 Maori patients with rheumatic fever and rheumatic heart disease. ${ }^{2}$ Falk et al, however, found that a decrease in HLA-A3 was the only difference between white patients and controls. ${ }^{3}$ These and other similar studies ${ }^{4}$ did not contain data on the HLA-DR antigen. None the less, this is the antigen that is likely to be important in disorders mediated by an abnormal immunological response. ${ }^{5}$

We have re-examined the possible role of HLA antigens, in particular the DR antigens, in predisposing individuals to rheumatic fever and its complications.

\section{Patients and methods}

Only patients with acute rheumatic fever that

Requests for reprints to Dr C N A Rajapakse, Department of Medicine (38), College of Medicine, King Saud University, PO Box 2925, Riyadh 11461, Saudi Arabia.

Accepted for publication 3 June 1987 fulfilled the Ducket Jones criteria ${ }^{6}$ or chronic rheumatic valvar heart disease were studied. Chronic disease was diagnosed in patients aged 12-60 years with clinical and echocardiographic evidence of either stenosis or regurgitation of both the mitral and aortic valves and a history suggestive of rheumatic fever. Those with no history of rheumatic fever or with only one affected valve were excluded from the study.

We studied consecutive outpatients or inpatients attending the rheumatic fever and medical clinics and medical wards of the King Khalid University Hospital in Riyadh. Only Arab patients were studied. Clinical conclusions about the nature of a cardiac abnormality were always confirmed with echocardiography. In patients with active arthritis other possible articular diseases such as rheumatoid arthritis were excluded by careful clinical and serological evaluation.

The controls were all Saudi nationals of Arab origin. They were healthy, symptom free, unrelated volunteer medical students and staff members of the King Khalid University Hospital.

Fifty seven Arab (Saudi and non-Saudi) patients with acute rheumatic fever or chronic rheumatic valve heart disease were HLA typed and 17 who were non-Saudi Arabs were excluded from the statistical comparisons because all the controls were Saudis. 
660

Lymphocyte suspensions for HLA typing were prepared from freshly drawn human peripheral blood by defibrination.

$A, B$, and $C$ antigens were determined by the standard two stage microlymphocytotoxicity technique. ${ }^{8}$ Tissue typing trays covering all 1984 International Histocompatibility workshop specificities were obtained from One Lambda Inc. A minimum of at least 3-4 sera for each specificity were used. Each cell suspension was typed at least twice.

For HLA-DR antigens too we used 50 sera obtained from One Lambda Inc and covering all specificities. These had been characterised by separate sequential serological screening. We used the $B$ cell lymphocytotoxicity method $(2 \mathrm{~h}$ with antiserum, $1 \mathrm{~h}$ with rabbit complement), with enriched B lymphocyte suspensions, prepared from the peripheral lymphocytes in nylon wool columns. ${ }^{9}$

We compared the frequency of the different HLA antigens in patients with acute rheumatic fever and chronic rheumatic heart disease as a whole and the controls. We also separately compared the individual groups-that is those with rheumatic fever and chronic rheumatic heart disease with the controls and with the other disease group. The $\chi^{2}$ test was used for these comparisons and significance levels were corrected for the number of sites tested.

\section{Results}

We studied 16 male and 24 female Saudi patients (mean age 21.4 years, range 13 to 53 years). Twenty five had chronic rheumatic valvar heart disease and
Rajapakse, Halim, Al-Orainey, Al-Nozha, Al-Aska

15 had acute rheumatic fever without evidence of chronic valvar heart disease. We also studied 17 non-Saudi Arabs (nine males and eight females; mean age 28 years, range $12-48$ years).

The frequencies of the $A$ or $B$ antigens were not significantly different in the patients as a whole and the controls (table 1 ).

Of the HLA-DR antigens, only DR4 was significantly different in the Saudi population as a whole and the controls $-65 \%$ in patients vs $12 \%$ in controls, $p<0.01$ after correction for the 10 antigens tested, relative risk ${ }^{10} 13.6$ with $95 \%$ confidence interval of 10.5 to 16.7 (table 1). HLA-DR4 was also more common in patients with chronic rheumatic valvar heart disease $(72 \%(18 / 25))$ than in the controls $(p<0.01)$ and in those with acute rheumatic fever without chronic valvar heart disease $(53 \%$ $(7 / 14))(p<0.01)$. Eighteen of the 26 patients with HLA-DR4 had valvar heart disease while only seven of the 14 without HLA-DR4 had valvar heart disease (table 2).

Although HLA-DR4 was more common in patients with rheumatic heart disease $(72 \%(18 / 25))$ than in those with acute rheumatic fever without evidence of chronic valvular disease $(53 \%(7 / 14))$ this trend was not statistically significant. The frequency of HLA-DR4 was particularly high among the two most common chronic valvar abnormalities that we saw-that is mitral stenosis $(83 \%$ (10/12)) and aortic incompetence $(70 \%(7 / 10))$.

The frequency of HLA-DR4 among the 17 nonSaudi Arabs with acute rheumatic fever or chronic rheumatic valvar heart disease was identical to that in the group of Saudi patients $(65 \%(11 / 17))$.

Table 1 Frequency of HLA antigens in Saudi patients with acute rheumatic fever or chronic rheumatic heart disease and in Saudi controls

\begin{tabular}{|c|c|c|c|c|c|c|c|c|c|c|c|}
\hline$H L A-A$ & $\begin{array}{l}C(\%) \\
n=100\end{array}$ & $\begin{array}{l}P_{t} \% \\
n=40\end{array}$ & $H L A-B$ & $\begin{array}{l}C(\%) \\
n=100\end{array}$ & $\begin{array}{l}P t \% \\
n=40\end{array}$ & $H L A-C$ & $\begin{array}{l}C(\%) \\
n=100\end{array}$ & $\begin{array}{l}P t \% \\
n=40\end{array}$ & $H L A-D R$ & $\begin{array}{l}C(\%) \\
n=100\end{array}$ & $\begin{array}{l}P t \% \\
n=40\end{array}$ \\
\hline $\begin{array}{l}\text { A1 } \\
\text { A2 } \\
\text { A3 } \\
\text { A9 } \\
\text { A10 } \\
\text { A11 } \\
\text { A19 } \\
\text { A28 } \\
\text { A29 } \\
\text { A34 }\end{array}$ & $\begin{array}{r}25 \\
47 \\
10 \\
28 \\
10 \\
10 \\
36 \\
18 \\
0 \\
3\end{array}$ & $\begin{array}{l}25 \\
40 \\
20 \\
38 \\
18 \\
10 \\
25 \\
18 \\
3 \\
0\end{array}$ & $\begin{array}{l}\text { B5 } \\
\text { B7 } \\
\text { B8 } \\
\text { B12 } \\
\text { B13 } \\
\text { B14 } \\
\text { B15 } \\
\text { B16 } \\
\text { B17 } \\
\text { B18 } \\
\text { B21 } \\
\text { Bw22 } \\
\text { B27 } \\
\text { B35 } \\
\text { B40 } \\
\text { Bw41 } \\
\text { Bw42 } \\
\text { Bw46 }\end{array}$ & $\begin{array}{r}26 \\
15 \\
15 \\
9 \\
2 \\
8 \\
9 \\
7 \\
13 \\
8 \\
21 \\
2 \\
2 \\
33 \\
4 \\
10 \\
1 \\
0\end{array}$ & $\begin{array}{r}33 \\
18 \\
10 \\
18 \\
8 \\
10 \\
0 \\
0 \\
13 \\
0 \\
30 \\
0 \\
3 \\
13 \\
8 \\
8 \\
0 \\
0\end{array}$ & $\begin{array}{l}\text { Cw1 } \\
\text { Cw2 } \\
\text { Cw3 } \\
\text { Cw4 } \\
\text { Cw5 } \\
\text { Cw6 } \\
\text { Cw7 }\end{array}$ & $\begin{array}{r}11 \\
9 \\
8 \\
31 \\
6 \\
11 \\
29\end{array}$ & $\begin{array}{r}0 \\
25 \\
10 \\
20 \\
3 \\
13 \\
10\end{array}$ & $\begin{array}{l}\text { DR1 } \\
\text { DR2 } \\
\text { DR3 } \\
\text { DR4 } \\
\text { DR5 } \\
\text { DRw6 } \\
\text { DR7 } \\
\text { DRw8 } \\
\text { DRw9 } \\
\text { DRw10 }\end{array}$ & $\begin{array}{l}28 \\
34 \\
38 \\
12 \\
15 \\
11 \\
28 \\
6 \\
1 \\
3\end{array}$ & $\begin{array}{c}15 \\
45 \\
18 \\
65^{\star} \\
10 \\
3 \\
25 \\
0 \\
0 \\
0\end{array}$ \\
\hline
\end{tabular}

${ }^{\star} \mathrm{p}<0.01$ compared with controls.

$\mathrm{C}$, controls (Saudis only); Pt, patients. 
Table 2 Comparison of frequency of HLA-DR4 in Saudi patients with or without valvar heart disease

\begin{tabular}{lccc}
\hline & $D R 4+v e$ & $D R 4-v e$ & Total \\
\hline Chronic rheumatic valvar heart disease & $18(72 \%)$ & $7(28 \%)$ & $25(100 \%)$ \\
Acute rheumatic fever with no valvar heart disease & $8(53 \%)$ & $7(47 \%)$ & $15(100 \%)$ \\
Total & 26 & 14 & 40 \\
\hline
\end{tabular}

\section{Discussion}

Because all our patients had both mitral and aortic valve disease we feel confident that patients with valve disease with other aetiologies, such as mitral valve prolapse, were not included in our study. A past history of rheumatic fever in all our patients further strengthens this confidence.

Our results suggest that HLA-DR4 predisposes individuals to both acute rheumatic fever and chronic rheumatic valvar heart disease. These results complement the findings of two recent studies reported after we had started this study. Ayoub found HLA-DR4 in eight out of 10 white American patients with rheumatic fever. ${ }^{11}$ Patarroyo found an alloantigen designated 883 in $66 \%$ of his patients with rheumatic fever. ${ }^{12}$ Indirect evidence suggested that this undefined 883 antigen may be associated with the DR locus. ${ }^{12}$

Our results, however, are in conflict with the findings of Jhinghan et al from India who reported no association with HLA-DR4 but an association with HLA-DR3 in their patients with "rheumatic heart disease". ${ }^{13}$ Whereas our patients had carefully documented evidence for a diagnosis of rheumatic fever or rheumatic heart disease no inclusion criteria were mentioned for the Indian patients. Also only 78 of these 132 Indian patients gave a past history of rheumatic fever and the positive association with HLA-DR3 was found almost entirely in the 56 patients without any past history that was suggestive of rheumatic fever. It is therefore possible that Jhinghan $e t$ al $^{13}$ studied a heterogenous group of patients with heart disease in which rheumatic fever was only one of many aetiologies. Alternatively, this conflict in results may reflect a true racial variation in the predisposition to rheumatic fever. Ayoub found that the high frequency of HLA-DR4 that he found in white patients was not present in the small group of black American patients. ${ }^{11}$ The almost identical HLA-DR4 frequency that we report in both Saudi and non-Saudi Arabs suggests that this distribution at least holds good for all Arabs.

HLA-DR4 is significantly more common in patients with rheumatoid arthritis. ${ }^{14}$ Our finding of an additional association with rheumatic fever and rheumatic heart disease suggests that HLA-DR4 positive individuals are susceptible to developing autoimmune diseases of connective tissue. This is the tissue common to both the joints and the cardiac valves-the structures that are affected in rheumatic fever, rheumatic heart diseases, and rheumatoid arthritis. This suggestion also complements the finding that HLA-DR4 positive individuals show a heightened responsiveness to collagen. ${ }^{15}$

It is probable that this abnormal immunological response directed against connective tissue may be initiated by many factors, in the case of rheumatic fever Streptococcus pyogenes. HLA-DR4 has been shown to be significantly more common in patients with post-streptococcal glomerulonephritis, ${ }^{16}$ suggesting that heightened responsiveness to streptococci was another factor predisposing HLA-DR4 positive individuals to rheumatic fever and rheumatic heart disease. Recently, a heightened responsiveness to Myobacterium tuberculosis has also been reported in HLA-DR4 positive individuals. ${ }^{17}$

We hope to confirm our results by extending the study to families of individuals affected by rheumatic fever and rheumatic heart disease.

We thank Dr A Lambourne of the Department of Community Medicine, College of Medicine, King Saud University, for his help in the statistical analysis of the results and the College of Medicine Research Council who funded this project.

\section{References}

1 Cheadle WB. Harveian lectures on the various manifestations as exemplified in childhood and early life. Lancet 1889;i:821-71,921.

2 Caughey DE, Douglas R, Wilson W, Hassal I. HLA antigens in Europeans and Maoris with rheumatic fever and rheumatic heart disease. $J$ Rheumatol 1975;2:319-22.

3 Falk JA, Fleichman JL, Brinskie JB, Falk RE. A study of HLA antigen phenotypes in rheumatic fever and rheumatic heart disease patients. Tissue Antigens 1973;3:173-8.

4 Tiwari JL, Terasaki PI. Cardiovascular diseases. In: Tiwari JL, Terasaki PI, eds. HLA and disease associations. New York: Springer Verlag, 1985:352-62.

5 Tiwari JL, Terasaki PI. Overview, rheumatology and 
joint diseases. In: Tiwari JL, Terasaki PI, eds. $H L A$ and disease associations. New York: Springer Verlag, 1985:32-111.

6 Jones TD. Diagnosis of rheumatic fever. JAMA 1944;126:481.

7 Ronkotein DE, Bauer W, Dofran A. Jones criteria (modified) for guidance of rheumatic fever. Circulation 1956;13:617-20.

8 Terasaki PI, McClelland JD. Microdroplet assay of human serum cytotoxins. Nature 1964;204: 998-1000.

9 Danilous J, Terasaki PI, Park MS, Ayoub GB. B Lymphocyte isolation by thrombin-nylon wool. In: Terasaki PL, ed. Histocompatibility testing. Los Angeles: UCLA Tissue Typing Laboratory, 1980:287-8.

10 Svejaard A, Platz P, Ryder LO, Staub Wilson L, Thompson M. HLA and disease associations: a survey. Transplant Rev 1975;22:3-43.

11 Ayoub EM. The search for genetic determinants of susceptibility to rheumatic fever: the missing link. Circulation 1984;69:197-201.

12 Patarroyo ME, Winchester RJ, Vejerano A, et al. Asso-
Rajapakse, Halim, Al-Orainey, Al-Nozha, Al-Aska ciations of a B cells alloantigen with susceptibility to rheumatic fever. Nature 1979;278:173-4.

13 Jhinghan B, Mehra NK, Randy KS, Taneja MC, Bhatia ML. HLA blood groups, and secretor status in patients with established rheumatic fever and rheumatic heart disease. Tissue Antigens 1986;27:172-8.

14 Panayi GS, Wooley P, Bachelor JR. Genetic basis of rheumatoid disease, HLA antigens, disease manifestations, and toxic reactions to drugs. $\mathrm{Br} \mathrm{Med}$ $J$ 1978;ii:1326-8.

15 Solingar AM, Bhatnager R, Stobo JD. Cellular molecular and genetic characteristics of $T$ cells reactivity to collagen in man. Proc Natl Acad Sci USA 1981;78:3877-8.

16 Layrisse Z, Rodriguez I, Garcia Ramirez R, Rodriguez A, Tiwari J. Family studies in HLA system in acute streptococcal glomerulonephritis. Immunology 1983;7:177-85.

17 Ottenhoff THM, Torres P, de las Aguas JT, et al. Evidence for an HLA-DR4-associated immune response gene for mycobacterium tuberculosis: a clue to the pathogenesis of rheumatoid arthritis? Lancet 1986;ii: 310-2. 